V.I. Lobov, K.V. Lobova

\title{
THE THYRISTOR CONVERTER INFLUENCE ON THE PULSATIONS OF THE ELECTROMAGNETIC TORQUE OF THE INDUCTION MOTOR AT PARAMETRICAL CONTROL
}

\begin{abstract}
Purpose. The purpose of the work is to identify the parameters influence of the electric motor, the power circuits elements of the converters, built on resistor-thyristor modules, the static torque and the moment of inertia of the mechanism on the vibrational components of the induction motor's electromagnetic moment. Methodology. The methodological basis for the solution of the task is an integrated approach. The application of the generalized control circuit for an induction electric motor and its mathematical description made it possible to analyze various power circuits of parametric control of an induction electric motor. To create a common control algorithm, effectively use the computer for calculations. To perform qualitative and quantitative analysis of the amplitudes and frequencies of the vibrational components of the electromagnetic torque of the electric motor. Results. The conducted researches allowed to reveal the peculiarities of the effect of the parameters of the elements of various types of power circuits of the parametric control converters on the vibrational components of the electromagnetic torque of an induction electric motor. Calculations and physical modeling have been performed, it has been possible to establish the conditions for the occurrence of electromagnetic pulsations and to determine the ways of their elimination. It was found that the magnitude of pulsations of the electromagnetic moment of an induction electric motor in quasi-permanent modes depends on the selected power circuit of the converter's stator and rotor commutators, the composition of the elements included in them, and the connection circuits. Comparison of calculated and experimental waveform when starting induction electric motors indicates that the pulsation of the electromagnetic torque is affected by: the size of the opening angle of the valves, their control methods, the rotor speed, the parameters of the electric motor and the mechanism are static and inertial moments. At the same time, it was revealed that the use of resistor-thyristor modules in the power circuits of the stator and rotary commutators reduces the magnitude of the pulsation of the electromagnetic torque of the induction electric motor. Increase the value of its maximum and average torques. Limit the magnitude of the shock and alternating torques when it starts and the transition from one speed to another. Scientific novelty. It is proposed to use a generalized circuit of parametric control of an induction electric motor for studying the change in the electromagnetic torque. The circuit consists of resistor - thyristor modules in stator and rotary commutators. The presented technique allowed simultaneously to investigate transients during the control of an induction electric motor by various power circuits of converters. The results of calculations allow choosing the necessary power circuit, taking into account the vibrational components of the electromagnetic torque of the induction motor. References 11, tables 1, figures 4.

Key words: induction electric motor, generalized circuit, thyristor converter, pulsations.
\end{abstract}

Представлены расчеты и физическое моделирование колебательных составляющих электромагнитного момента при изменении параметров асинхронного электродвигателя, элементов силовых схем преобразователей, построенных на резисторно-тиристорных модулях. Установлено, что величина пульсаций электромагнитного момента в квазипостоянных режимах зависит от выбранной силовой схемы статорной и роторной коммутаторов преобразователя, состава элементов, входящих в них, и схемы их соединения, изменения величины углов открытия вентилями, способы их управления, частота вращения ротора, параметры механизма - моменты статический и инерции. Предложено использовать для исследования обобщенную схему параметрического управления асинхронного электродвигателя. Библ. 11, табл. 1, рис. 4.

Ключевые слова: асинхронный электродвигатель, обобщенная схема, тиристорный преобразователь, пульсации.

Problem definition. Power circuits for converters for controlling induction motors (IMs) are constructed using various elements - resistors, inductors, diodes, thyristors, etc. Converters using these elements are included in the stator, rotary or simultaneously in the stator and rotor circuits of the IM and are referenced to parametric control converters $[1,2]$. Depending on the power circuit of the converter, respectively, the static and dynamic characteristics of the IM are changed. Circuits of converters in different ways determine the starting, brake, reversing, power characteristics of IM. When loading the IM controlled by such converters, there are dynamic forces in the elements of the kinematic chain, which can be detected in transient and steady modes of operation due to fluctuations of the electromagnetic torque (ET) of the IM.

It is known that the ET contains the mean and oscillatory components, but how the latter one varies, with what frequency, depending on the chosen power circuit of the converter and the location of the connection of its elements in the circuit, has not been investigated. The ET pulsations caused by the influence of higher harmonics of voltage on the IM lead to deterioration of the vibration and acoustic characteristics of the IM and mechanism, that is, the noise and vibration are increased. This phenomenon is accompanied by resonance phenomena and the deterioration of the strength of mechanical equipment of the electric drive and the mechanism. With an increase in the moment of inertia, the number of pulsations of IM increases. Particularly large values of maximum throwing torques are achieved with reverse of IM. However, to date, for some types of converters there are no investigations and is not defined as the value of electromagnetic oscillations of the ET

(C) V.I. Lobov, K.V. Lobova 
depending on the IM and electric circuit parameters, chosen converter circuits, the value of opening angles of thyristors, a way to control the valves, rotor speed, and more. Therefore, these phenomena require a thorough investigation.

For an integrated approach and systematic analysis, finding or obtaining rational variants of power circuits of converters with parametric control of IM, it is most convenient to use a generalized (common) power circuit and its mathematical description, which allows to create a general control algorithm and to use effectively computers conducting investigations (Fig. 1,a).

The sequential connection of a power thyristor with an active resistor, parallel to which the second additional resistor is connected, forms a module that is not only a separate functional module but can also be a constructively manufactured block called a resistor-thyristor module (RTM). As can be seen from Fig. 1, $a$, a generalized power circuit of the converter of the IM control consists of stator (SC) and rotor (RC) commutators.

Let us consider possibilities of the proposed generalized converter circuit with RTM in stator circuits indicated for RTM1 - RTM6 as: $R_{s i}$ and $r_{s i}$ and for rotor circuits RTM7 - RTM12 as: $R_{r i}$ i $r_{r i}$, at the condition that:

$$
R_{s i}=R_{s} ; R_{r i}=R_{r} ; r_{s i}=r_{s} ; r_{r i}=r_{r},
$$

where $i=1,2, \ldots$ for boundary $(0, \infty)$ and intermediate values of $R_{s}, r_{s}, R_{r}$ and $r_{r}$ and three devices $Z_{0}, Z_{s}, Z_{i}$, of the communication module kind of $Z$.

In accordance with the accepted constraints in the tables (Fig. 1,b,c), the possible variants of the power circuits for the SC and the RC are respectively indicated, which are indicated by: $S_{i j}$ and $Z_{k i j}$. The $i j$ indexes in the tables indicate the serial number of the corresponding row and column, and the index $k$ takes values $0, s, i$, that is, indicates the type of communication module $Z$ and forms a DC link. In module $Z$ separately three different devices are used: $Z_{0}, Z_{s}, Z_{i}$ forming corresponding groups of RC.

In the first group $Z_{0}$ devices are included that shorten a DC circuit, in the second group $Z_{s}$ - allow you to discretely change the value of the parameters of elements $Z$, and the third group $Z_{i}$ - carry out impulse control of these parameters. However, in the communication module of the $Z$-type the value of the resistance of the active resistor included between the points $P$ and $N$ is changed according to a certain law.

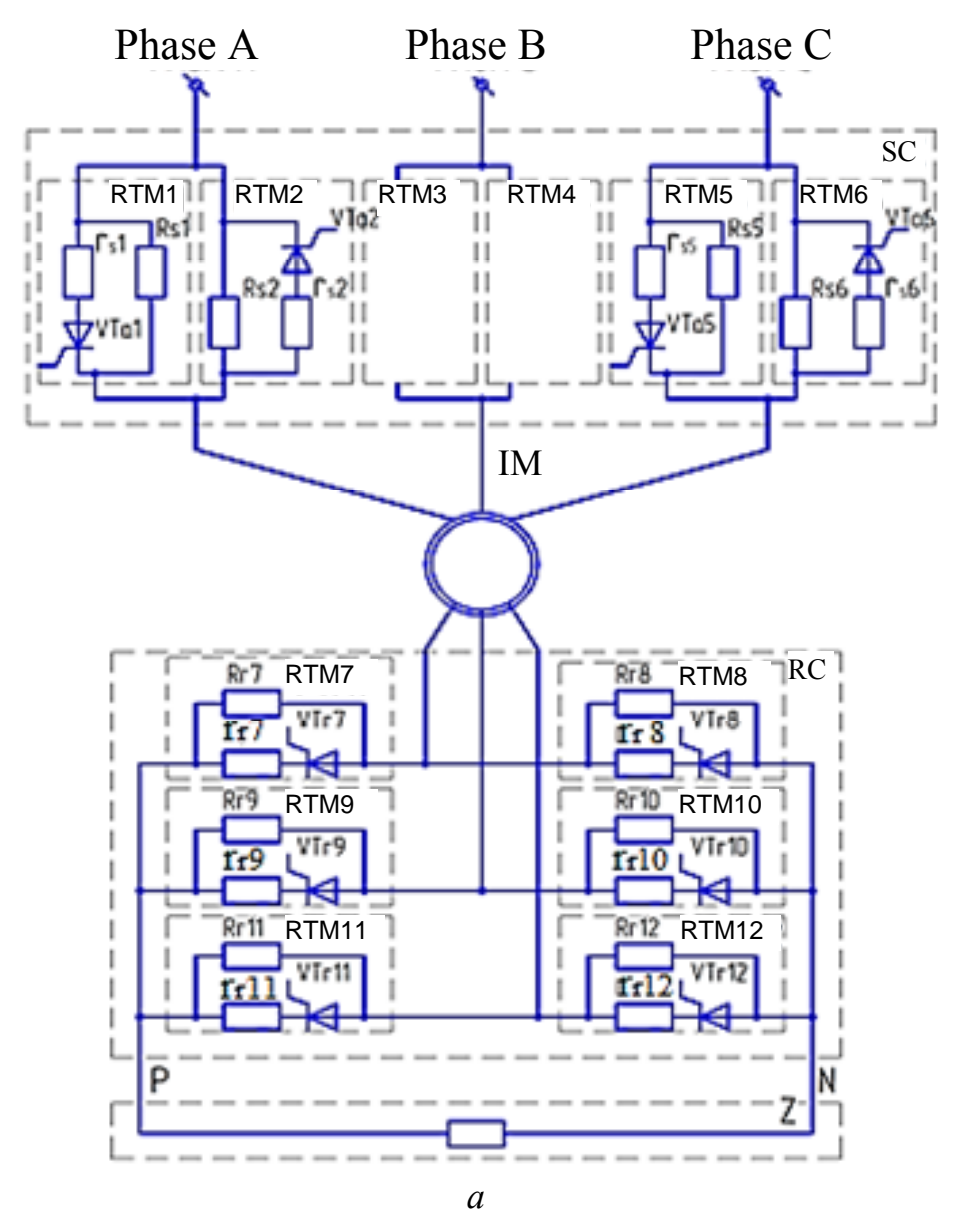

\begin{tabular}{|c|c|c|c|}
\hline \multirow{2}{*}{$r_{s i}$} & \multicolumn{3}{|c|}{$R_{s i}$} \\
\cline { 2 - 4 } & 0 & const & $\infty$ \\
\hline 0 & $S_{11}$ & $S_{12}$ & $S_{13}$ \\
\hline const & $S_{21}$ & $S_{22}$ & $S_{23}$ \\
\hline$\infty$ & $S_{31}$ & $S_{32}$ & $S_{33}$ \\
\hline
\end{tabular}

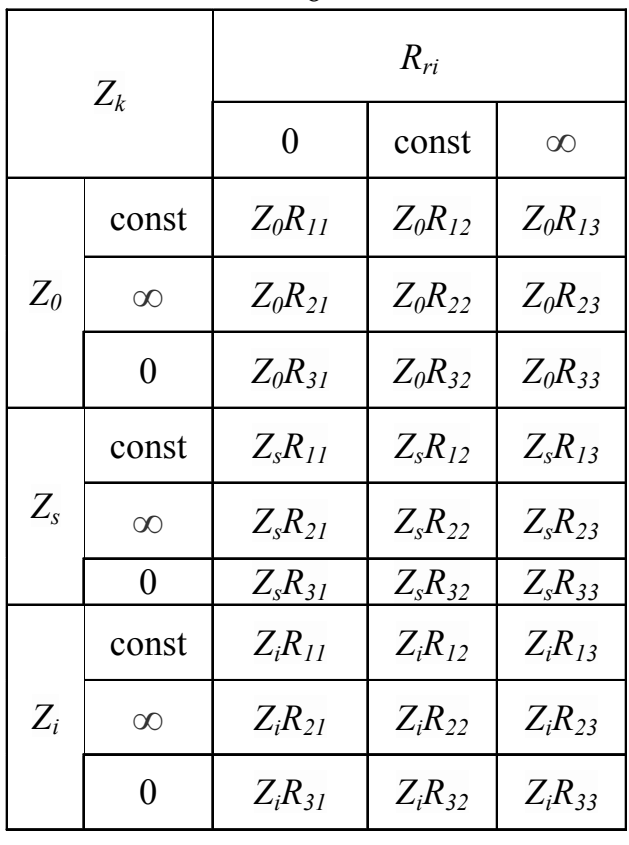

$c$

Fig. 1. Generalized power circuit of parametric control of IM with SC and RC as a part of the converter $(a)$ and variants of power circuits: SC $(b)$ and $\mathrm{RC}(c)$ 
Despite the introduction of constraints, the variant of the proposed generalized circuit of the converter encompasses many known circuits of parametric control of IM, as illustrated by the following examples. A separate parametric control circuit using thyristors in the stator of type $S_{13}$ is known as a nonreversible thyristor voltage regulator (TVR). In circuit $S_{13} R_{s i}=\infty$ and $r_{r}=0$ are adopted, that is, in each phase of the IM stator two thyristors are connected, which are connected to each other in a counter-parallel circuit. If in SC $R_{S i}=$ const and $r_{r}=0$ are taken, then in each phase of the IM only $R_{s i}$ resistor will remain. Another circuit of $S_{12}$ type is provided for the case where $R_{s i}=$ const and $r_{s i}=0$. Stator windings of the IM in the $S_{12}$ type circuit are connected to the supply network via RTM. In the circuit of type $S_{12}$, RTM contains one resistor $R_{s i}$, in parallel with which the thyristor $V T_{i}$ is connected. Moreover, in each phase of the stator of the IM two RTM are connected, interconnected counter-parallel.

We pay attention to the fact that the converters, which have in their composition valve elements with incomplete control (thyristors or simistors), included in the circuit of alternating current, operate in the mode of natural switching. This type of converters implements the phase control in the stator or rotor circuits of the IM.

Fig. 1,c presents twenty-seven different options for power control circuits for IM rotor circuits. Options for power control circuits for IM rotor $Z_{0} R_{11}, Z_{0} R_{21}, Z_{0} R_{11}$, $Z_{0} R_{21}, Z_{0} R_{31}, Z_{s} R_{11}, Z_{s} R_{21}, Z_{s} R_{31}, Z_{i} R_{11}, Z_{i} R_{21}, Z_{i} R_{31}$ at $R_{r i}=0$ provide only closing rotor windings to the overall connection point, making thus normal rotor as shortcircuited. According to the circuit of generalized parametric control of IM at $R_{r i}=$ const and $r_{r i}=$ const in each phase of the rotor of the IM parallel to resistance $R_{r i}$ a circuit of serial interconnected resistors $r_{r i}$ and thyristors $V T_{i}$ is connected, and at $R_{r i}=\infty$ and $r_{r i}=$ const - only a serial connected circuit of these elements remains. All this leads to different power circuits. Thus, at $R_{r i}=$ const varieties types of schemes are produced: $Z_{k} R_{12}, Z_{k} R_{22}$ and $Z_{k} R_{32}$, and at $R_{r i}=Z_{k} R_{13}, Z_{k} R_{23}, Z_{k} R_{33}$, and also a number of other circuits presented in Fig. 1,c. Circuit of type $Z_{k} R_{13}$ at $r_{r i}=0$ is known as Larionov bridge circuit, in the DC circuit of which communication module type $Z_{k}$ is connected. Two other circuits type $Z_{k} R_{22}\left(R_{r i}=\right.$ const and $r_{r i}=$ const and $Z_{k}=\infty$ ) and $Z_{k} R_{23}$ (at $R_{r i}=\infty$ and $r_{r i}=$ const and $Z_{k}=\infty$ ) have no open DC circuit, therefore they can be used independently.

Applying the communication module of $Z$ type, the corresponding $Z_{0}$ circuit of $Z_{k} R_{22}$ type is converted into $Z_{0} R_{32}$ type circuit, and $Z_{k} R_{23}$ type circuit, respectively, into $Z_{0} R_{33}$ type circuit. In addition, from circuit of type $Z_{0} R_{32}$ with $R_{r i}=\infty$ and $r_{r i}=$ const there is already a new circuit of type $Z_{0} r_{13}$, and when $R_{r i}=$ const i $r_{r i}=\infty$, the circuit of type $Z_{0} r_{22}$, containing only additional resistors in the rotor circuit is quite commonly used in industrial conditions. When $R_{r i}=$ const i $r_{r i}=0$, we get circuit of type $Z_{0} R_{32}$ and at $R_{r i}=$ const, $r_{r i}=0$ - type $Z_{0} r_{33}$. Similarly, from circuit $Z_{0} R_{33}$ at $r_{r i}=0$, another circuit of $Z_{0} r_{33}$ type, in which the rotor windings are connected to the «star» circuit and are connected sequentially to the thyristors and resistors, which are closed to each other to a zero point, is formed. The power structure of the RC will change considerably for $Z_{0} R_{32}$ type circuit if devices of type $Z_{s}$ or $Z_{i}$ are present in the DC circuit.

From the circuit of type $Z_{s(i)} R_{32}$ a rotor commutator is obtained, in which the thyristors are connected to the circuit of the triangle. In this case of the arrangement of $Z_{s}$ or $Z_{i}$, there is only one thyristor, connected in the DC circuit. If we assume that in the generalized scheme of type $Z_{s(i)} R_{32}$ resistors: $R_{r 1}=R_{r 2}=R_{r 3}=R_{r 4}=R_{r 5}=R_{r 6}=$ $=\infty, r_{r 2}=r_{r 3}=r_{r 5}=r_{r 6}=\infty=$ const, $r_{r l}=r_{r 4}=0$, then it turns out, that the triangular commutator is connected to the zero point of the connection of the IM rotor, and power circuit of type $Z_{1} R_{32}$ is obtained, in the rotor circuit there are no resistance resistors. If taken in the circuit of type $Z_{s(i)} R_{32}$ that $R_{r 1}=R_{r 4}=R_{r 5}=R_{r 6}=\infty=\mathrm{const}$, and $r_{r 1}=r_{r 4}=0, r_{r 2}=r_{r 3}=r_{r 5}=r_{r 6}=\infty=$ const, then the commutator will be connected by the $Z_{2} R_{32}$ circuit.

Thus, the use of a generalized converter circuit for parametric IM control will allow to use for the investigation of different power circuits of converters, which are obtained from the generalized one and solve the actual problem of determining the value of pulsations, overvoltages, amplitudes and frequencies of oscillating components of ET by simple engineering methods.

Analysis of previous investigations and publications. A large number of publications are devoted to the study of the control of IM in different operation modes. These questions are one of the key issues that are discussed today by experts. The authors do not provide sufficient information for the construction of automated systems of parametric control of IM, taking into account the change of electromagnetic torques, which essentially change on transients during start-ups, braking, reversal and operation. The main problem of IM, which researchers solve, is to reconcile the torque with the load torque, as during start-up, for example, torque for a fraction of second often reaches 150-200\%, which can lead to failure of the kinematic chain of the drive [3]. At the same time, high starting current at start can be 6-8 times more than nominal, causing problems with the stability of the supply and fluctuations of ET, the values of which in the presented information are not defined and are not presented. To eliminate some of these disadvantages, the industry manufactures controllers EnergySaver (soft starters with power saving function and power factor correction) which are intermediate between soft starters and frequency converters. EnergySaver uses the traditional for soft starters circuit of counter-parallel connected thyristors [4], that is, TVR, which upon closure of the start-up process are locked by contactors. The moment created by the IM, depends on the values of the applied voltage and sliding. The smaller the moment of loading is applied to the rotor, the more the rotor «catches up» with the stator field (sliding decreases), the further the IM becomes less economical. If appropriately reduce the supply voltage on the stator windings of IM, the sliding will return to the nominal value. The mechanical characteristics of the IM with reduced voltage on the stator windings have corresponding reduced ET. This will reduce the current flowing through the windings of the IM, and the consumed power is proportional to the product of the voltage and current, the loss decreases, the efficiency of the electric motor will increase [5]. 
However, there is no qualitative and quantitative analysis of changes in the amplitudes and frequency of oscillatory ET components in this work.

The analysis of the dynamic processes of energy transformation in IM is a complex task in connection with the essential nonlinearity of the equations describing IM, due to the product of variables. Therefore, the study of dynamic characteristics of IM should be conducted with the use of computers [6]. A common solution of the system of differential equations in the software environment MathCAD allows you to calculate graphs of transient processes of speed $\omega$ and ET $M$ at numerical values of parameters of the equivalent circuit of the IM. As the analysis of the dynamic mechanical characteristics of the IM shown [6], the maximum shock torques at direct starting exceed the nominal moment $M_{n}$ of static mechanical characteristic of more than 4.5 times and can achieve unacceptably high strength values from point of view of mechanical strength. Shock torques during startup, and especially at the reverse of the IM, lead to the failure of the kinematics of production mechanisms and the IM itself. At the same time, the oscillations of the torques of IM at the control of the converters are not defined.

Among the topical tasks in the field of IM control is the development of relatively simple and effective converters to expand the range of regulation of the rotation speed of the IM down from the nominal value. The possibility of transferring the electric drive to reduced rotational speeds allows us to realize the economic modes of operation when reducing the technological loads and extends its regulatory properties. The need for such regulation inevitably appears in the current production. Traditional systems of regulated IM with short-circuit motor «thyristor voltage regulator - induction motor» (TVR-IM) are oriented for soft start-up and for creation of braking modes [7]. The circuit involves voltage regulation by forming predetermined angles of thyristor control. The basis of such a converter is phase or pulsed control. This allows the use of relatively inexpensive single-acting thyristors, which have rather high energy performance [8]. When controlling such converters, it is necessary to increase the rotor rotation evenness by reducing the amplitude and/or controlling the frequency of the pulsations of the ET, distorted by the operation of the power elements of the converter [9].

Investigation of pulsations of ET in frequency converters with PWM inverter with constant and variable frequency is considered in work [10]. The results of research in this paper indicate the existence of this problem in the control of IM, but the calculation method can not be transferred to the calculation of torque oscillations for parametric control converters. The basis of converters with phase or impulse control is another power circuit, consisting of RTM [11]. Together with the obvious advantages of using simple converters constructed on the basis of RTM, as the analysis of scientific and technical literature shown, the question of determining the levels of pulsations of ET of IM was not thoroughly considered by specialists.

Methods of analytical calculations made for frequency converters, asynchronous-valve cascades or valve motors can be partially used to calculate ET pulses when controlling such types of converters. The main differences here are caused, as by a feature of regulating the value of current through controlled valves, as well as by possible circuits of connection of resistors, thyristors, stator and rotor windings of IM. In addition, it is known that at the IM in the process of regulation the values such as the angle of opening thyristors, the stator voltage, the EMF of the rotor, the stator and rotor currents, ET, its sliding and others change, and they are interconnected by the corresponding functional dependences [10]. The variation of the ET oscillations $\Delta M$ depends on the selected power circuits connected to the stator and the rotor, the values of the angles of opening the thyristors, the method for controlling the valves, the rotor speed, the parameters of the electric motor and the electric drive $[5,6,9]$.

When designing modern electric drives, it often becomes necessary to determine the dynamic forces in the elements of the kinematic chain, which can be detected in transient and steady modes of operation due to oscillations of the ET. In transient operating modes of the electric drive, the deviation of the shape of the voltage curve on the clamps of the IM from the sinusoidal one causes high-frequency oscillations of the ET and uneven rotor rotational frequency.

Determination of oscillating components of ET is of great practical importance, since they significantly affect not only the mechanical strength of the electric drive units and the state of the technological mechanism. If the frequencies of the natural oscillations of the mechanical part of the electric drive will be close to the frequencies of the oscillatory components of the ET, then there may be a danger of significant overvoltages in the elements of the electric drive.

The goal of the work is determination of the influence of the parameters of the electric motor, elements of power circuits of the converters constructed on the RTM, the static torque and the moment of inertia of the mechanism on the oscillatory components of the ET of the IM.

Investigation techniques. Comprehensive analysis of the diversity of power circuits for converters and the study of the main modes of IM is associated with a large amount of analytical calculations and the need for experimental research. Therefore, the methodological basis for solving the tasks is a comprehensive approach that allows the most convenient use of the generalized control circuit of the IM [11], its mathematical description, the general control algorithm and to conduct the study of the oscillatory components of the ET by mathematical modeling.

Material presentation and results. To assess the values of oscillations ET a generalized control circuit of the IM is used. The circuit has a converter consisting of stator and rotor commutators. Each commutator is implemented with RTM (Fig. 1,a). Using computers calculations of different operating modes of the IM are performed. It has been established that pulsations in some cases reach significant values. Thus, for the IM of type MTF 411-8, controlled by the power circuits of types $S_{13} Z_{0} r_{11}, S_{13} Z_{0} r_{22}, S_{13} Z_{0} r_{32}, S_{13} Z_{2} R_{32}, S_{22} Z_{k} R_{32}, S_{11} Z_{L} R_{33}$, the 
maximum $M_{\max }$, the minimum $M_{\min }$ and the mean $M_{\mathrm{m}}$ values of the ET are calculated. Using the calculated ET values, the oscillations $\Delta M$ are determined at different opening angles $\alpha_{s}, \alpha_{r}$ of the thyristors of the stator and rotor commutators and rotor rotation speeds $\omega_{r}$, respectively, equal to: minus $600,400,200$, plus 200,400

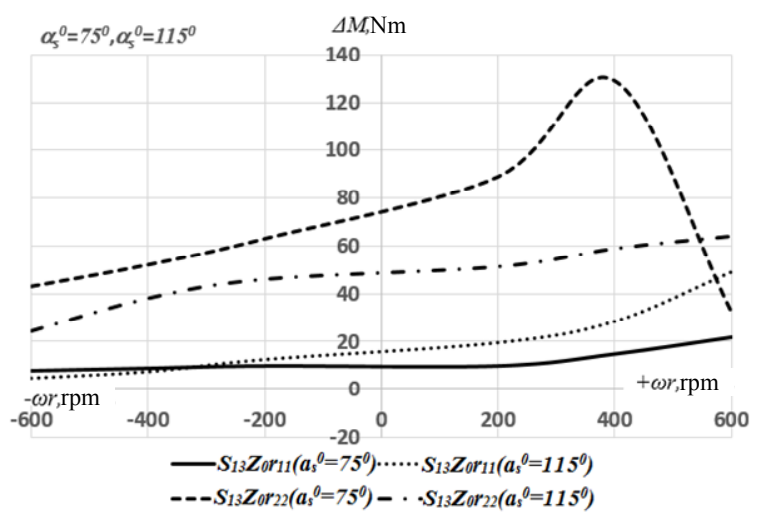

$a$

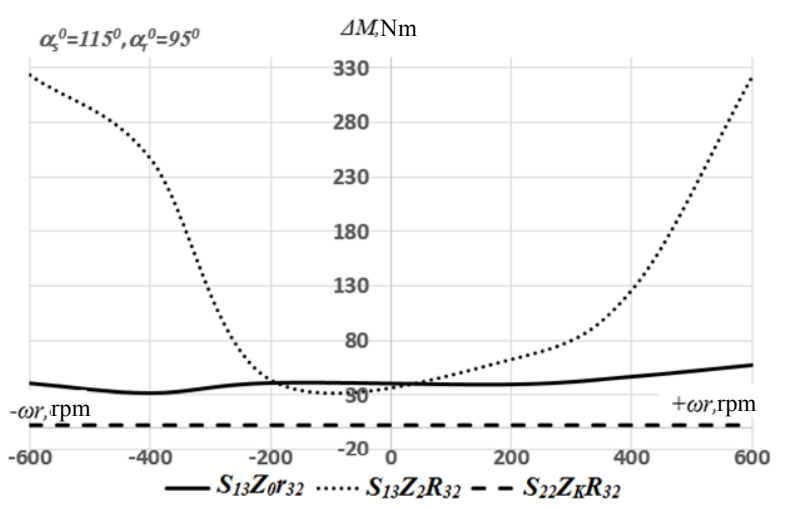

$c$ and $600 \mathrm{rpm}$. The results of calculations are summarized by the graphs presented in Fig. 2 .

The values of resistors' resistances of the RTM, included in the investigated power circuits, adopted in accordance with Table 1.

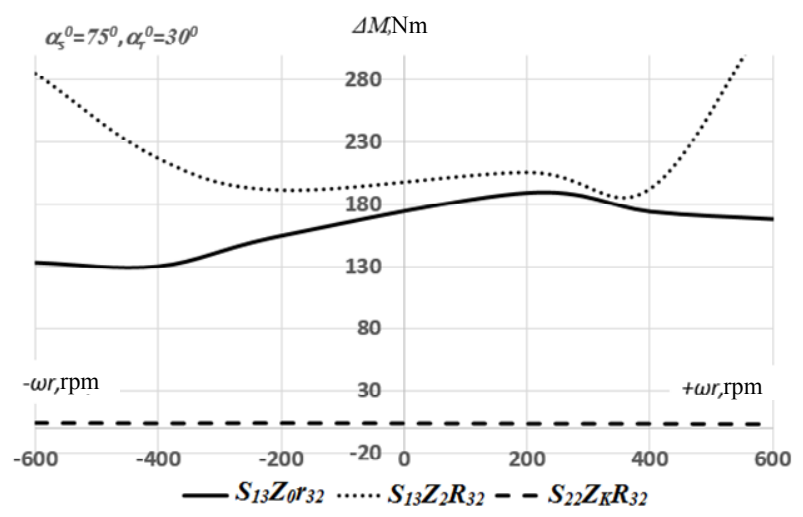

$b$

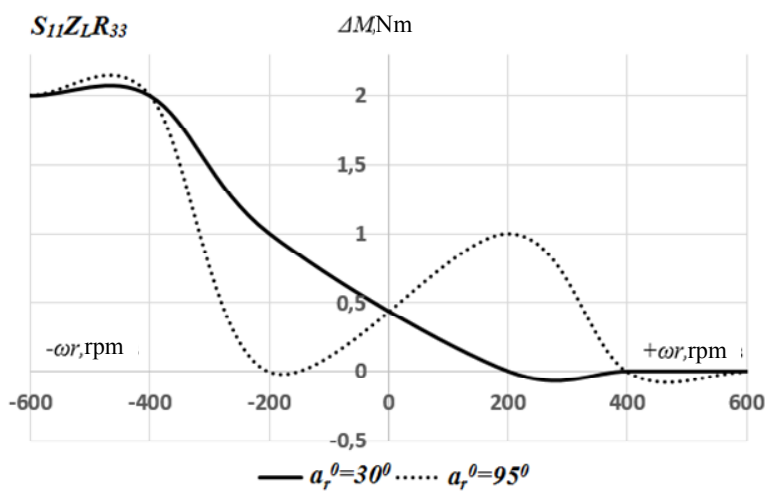

$d$

Fig. 2. Oscillations of the electromagnetic torque of the IM at the rotor rotation speeds, opening angles $\alpha_{s}, \alpha_{r}$ of thyristors of SC and RC for different power circuits

Table 1 the resistors of the RTM varies, the change of which

Values of the resistors' resistances of the RTM or circuits

\begin{tabular}{|c|c|c|c|c|}
\hline \multirow{2}{*}{ Type of power circuit } & \multicolumn{5}{|c|}{ Value of the resistors' resistances, $\Omega$} \\
\cline { 2 - 5 } & $R_{s i}$ & $R_{r i}$ & $r_{s i}$ & $r_{r i}$ \\
\hline$S_{13} Z_{0} r_{22}$ & - & 1.95 & - & - \\
$S_{13} Z_{0} r_{32}$ & - & 2.8 & - & - \\
$S_{13} Z_{2} R_{32}$ & - & 2.8 & - & - \\
$S_{22} Z_{K} R_{32}$ & 0.32 & 4.4 & 0.1 & 0.48 \\
$S_{11} Z_{L} R_{33}$ & - & 4.4 & - & 0.9 \\
\hline
\end{tabular}

In the circuits, the connection of RTM in series with the windings of IM causes the appearance of additional oscillations of components of ET, the frequency and amplitude of which are determined by the specificity of the operation of thyristors in the converter. When commutating by the valves resistors in the circuits of IM there is a quasi-steady mode, which is a sequence of transients. In this mode the structure of the power circuits of the IM changes. Intervals of the existence of structures for stator and rotor circuits are determined by the moment of supply of control impulses and the conditions of natural commutation of valves.

As a result of the change in the structure of the power circuits, the equivalent value of the resistance of leads to oscillations of stator and currents of IM. The latter, in turn, change the magnetic flux and ET of the electric motor. As calculations show (Fig. 2), the smallest fluctuations of the ET of the IM are provided by power circuits with separate control in the rotor circuit (type $S_{11} Z_{L} R_{33}$ ) and with compatible control in the stator and rotor circuits (type $S_{22} Z_{K} R_{32}$ ). The first circuit practically eliminates the oscillations of ET. This circuit increases $M_{m}$ and maintains it approximately at the nominal level throughout the all range of measurement of the frequency of rotation of the IM. The reduction of the pulsation of ET is achieved here due to the increase of the coefficient of attenuation of the current of the rotor circuit. It is increased by increasing the equivalent resistance of the resistors of RTM. The second circuit is inferior to the first one in the amplitude of the pulsations $\Delta M$ of the electric motor.

Increasing the opening angle $\alpha_{r}$ for the first circuit leads to increase in the maximum torque in the low velocity zone and decreases it at high velocity of the IM. This is due to the changing voltage harmonic composition of the IM. The connection of RTM in only two phases of 
the rotor (circuit of type $S_{13} Z_{2} R_{32}$ ) leads to significant oscillations of the ET of IM. A large value $\Delta M$ causes vibration, strong noise and strikes, so their value should be reduced to a minimum. The value of these oscillations is higher compared to other power circuits. For example, for this circuit at speed $n_{r}=600 \mathrm{rpm}$ and at angles $\alpha_{s}=75^{\circ}$ and $\alpha_{r}=30^{\circ} \Delta M$ reaches a value equal to $377 \mathrm{Nm}$, which is 1.5 times higher than the nominal torque of the IM. At rotation frequency of the rotor, equal to $400 \mathrm{rpm}$ and at angles $\alpha_{s}=115^{\circ}$ and $\alpha_{r}=95^{\circ} \Delta M$ reaches the value equal to its rated torque. In this case, the oscillation of the torque $\Delta M$ may reach a triple value of the critical torque of the IM. At the asymmetric connection of the elements of the converter in the rotor circuit, the ET of IM as in the case of single-phase connection, contains the average and vibrational components.

The amplitude of the oscillating component of the ET depends on the degree of asymmetry in the circuit of the rotor, and its frequency is always equal to twice the sliding frequency. As for the average torques of the IM, they are at phase control of the valves in the stator circuit (the circuit of type $S_{13} Z_{0} r_{32}$ ) increase with increasing rotor rotation speed and, conversely, decrease with the presence of additional resistors in the rotor circuit (circuit type $S_{13} Z_{0} r_{22}$ ) or RTM (circuits of types $S_{13} Z_{0} r_{32}, S_{13} Z_{2} r_{32}$, $\left.S_{13} Z_{k} r_{32}, S_{13} Z_{L} r_{32}\right)$. The average torque of the IM is changed slightly in the rotor rotational frequency control in the circuit with separate control in the rotor circuit
$\left(S_{11} Z_{L} r_{33}\right)$ and in the circuit with joint control in the stator and rotor circuits $\left(S_{22} Z_{K} r_{32}\right)$. For the first mentioned circuit, the value of the mean torque is greatest in the entire range of changes in the velocity of IM.

Thus, the use of RTM in the circuit of IM allows significantly reduce the value of pulsations of the ET, increase the value of the maximum and average torques and limit values of shock and alternating torques at the start as well as, as investigations have shown that the transition from one speed to another. The increase of the equivalent value of resistors' resistance of the RTM in the stator circuit slightly improves the power factor of the circuit, thereby shock alternating torques are reduced not only by lowering the voltage on the stator, but also by reducing their values and increase the damping aperiodic currents.

The moment of inertia of the electric drive has a significant impact on the duration and nature of the flow of transients. In Fig. 3 obtained on the computer and experimental installation oscillograms of the electric drive start in the presence on the IM shaft of different by their value additional flyweights. Analyzing these graphs, we can conclude that with increasing the moment of inertia of the electric drive the amount of considerable by their values shots of the transient IM at the beginning of the start process first increases and oscillations of the rotor rotation speed and ET near synchronous speed decrease. This is because some attenuation coefficients of free components of the ET at low speeds are very small.
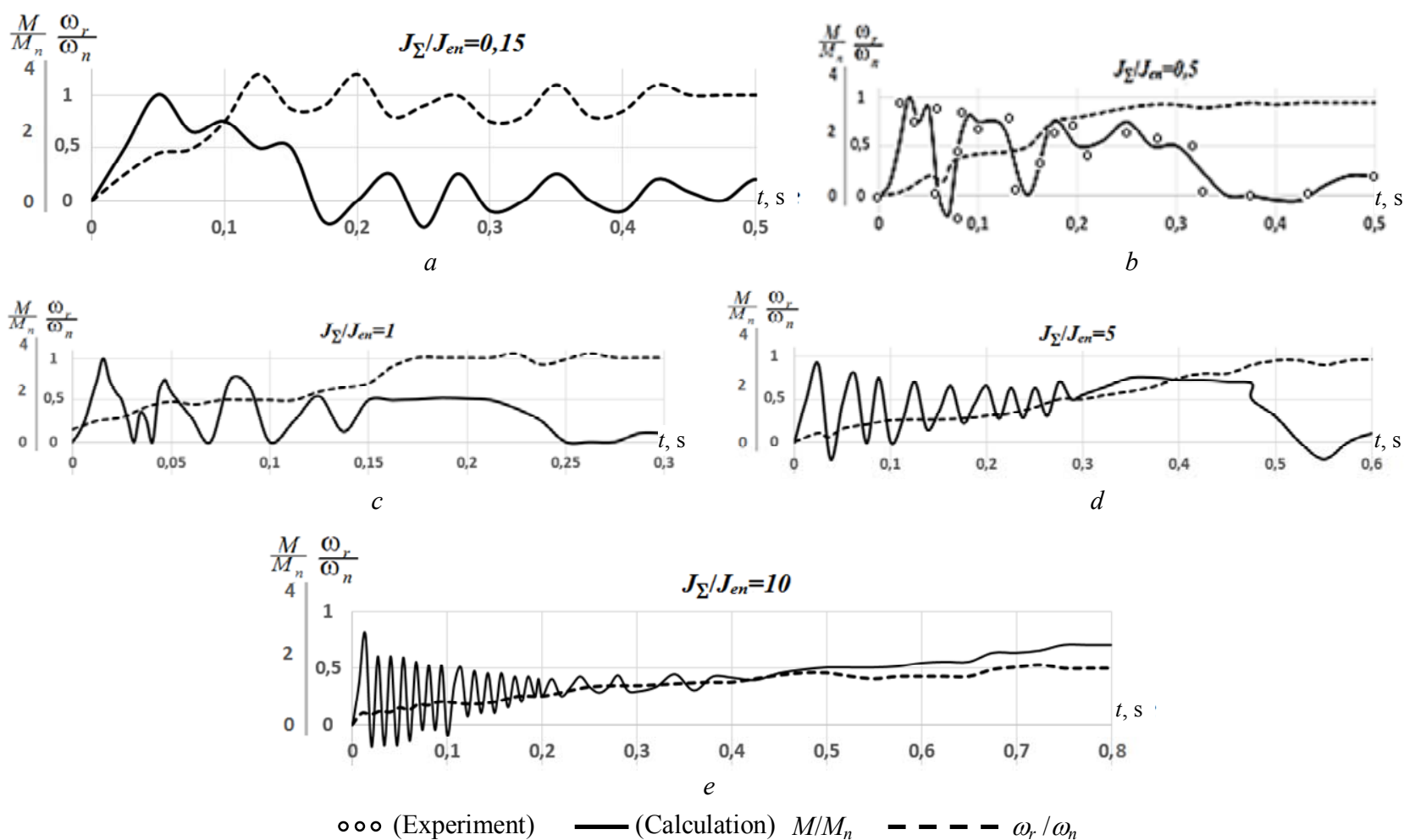

Fig. 3. Oscillograms of the electric drive start at different values of flyweights

If the increase the moment of inertia of the electric drive, then the IM will operate longer at reduced speeds, where the coefficients of attenuation of the stator and rotor circuits are small, which determines slower ET attenuation with increase in the total moment inertia $J_{\Sigma}$ of the electric drive and the mechanism. With increasing $J_{\Sigma}$, the frequency increases and the peak amplitude of the transient ET increases. From the beginning of the process 
with decreasing $J_{\Sigma}$ the number of these peaks reduces. However, in this case, the speed and ET oscillations increase in the zone of low sliding of the IM.

Comparison of a large number of calculated and experimental oscillograms for the IM of different power with normal and elevated sliding indicates that the results obtained when changing the total moment of inertia are adequate. The effect of the total moment of inertia on the transient process for other power control circuits of the IM is almost the same as for the $S_{13} Z_{0} r_{32}$ type circuit.

Increase in the static torque on the shaft of the IM also results in a more long-term course of the acceleration process (Fig. 4).
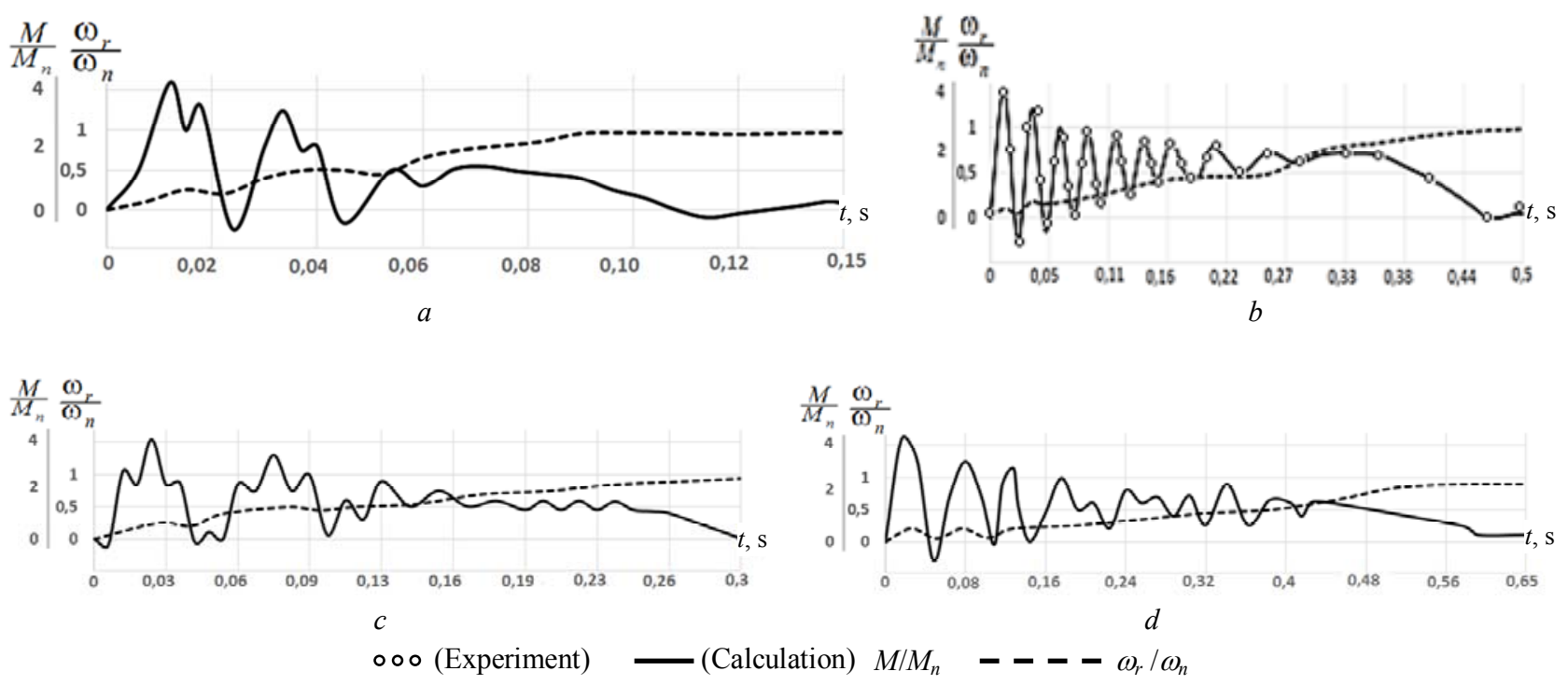

Fig. 4. Experimental and calculated oscillograms of the IM start at the change of the static torque for the circuit $S_{13} Z_{0} r_{11}: a-M_{s}=0, b-M_{s}=M_{n}$; and for the circuit $S_{13} Z_{0} r_{32}: c-M_{s}=0, d-M_{s}=M_{n}$

The frequency of pulsations of the ET at the beginning of the acceleration process increases. With the increase in the speed of the rotor, the frequency of pulsations significantly decreases, and in the region of the synchronous speed the torque oscillations completely disappear. The picture of the transient when changing the static torque looks like the picture of the transient when changing the moment of inertia. Oscillograms of the start of the IM with the change of the static torque on the shaft of the rotor shown in Fig. 4 for the two power circuit types $S_{13} Z_{0} r_{11}$ and $S_{13} Z_{0} r_{32}$ clearly confirm the above. For the first circuit, the opening angle $\alpha_{S}$ of the thyristors is assumed to be $90^{\circ}$, and for the second circuit the angles $\alpha_{S}$ and $\alpha_{r}$ respectively were $30^{\circ}$ and $60^{\circ}$. The results of modeling on the computer show that the picture of the transient for other power circuits when changing the load on the shaft of IM is similar to the transient created by the circuits of types $S_{13} Z_{0} r_{11}$ and $S_{13} Z_{0} r_{32}$. Their difference is manifested only in different oscillations of ET.

Conclusions and perspectives of further research. Thus, the conducted investigations allowed to reveal the peculiarities of the influence of the parameters of elements of different types of power circuits of converters constructed on RTM, on the amplitude and frequency of oscillatory components of the ET of the IM.

The performed mathematical and physical modeling allowed to establish the conditions for the occurrence of electromagnetic pulsations, to determine the ways to eliminate them and to confirm the effectiveness of the chosen research method. It is established that the value of the pulsations of the electromagnetic torque of the IM in the quasi-steady modes depends on the selected power circuit of the converter, the stator and rotor commutators, the composition of the elements included therein, and the circuits of their connection in the modules.

Comparison of calculated and experimental oscillograms of the IM start of different power with normal and increased sliding indicates that the impact on the pulsation of the ET is provided by the values of the angles of opening the valves, their control methods, the rotational speed of the rotor, the parameters of the electric motor and the mechanism - the static torque and the moment of inertia.

At the same time, it was discovered that the use of RTM in the power circuits of the stator and rotor commutators of the converter reduce the value of the pulsation of ET in IM and increase the value of its maximum and the average torques and limit the value of shock and alternating torques, both during its start and at the transition from one speed to another.

In future investigations, it is planned to focus on testing the developed methodology in industrial conditions.

\section{REFERENCES}

1. Marenich K.N., Burlaka A.N. Substantiation of the principle of parametric control of an asynchronous motor of a load stand in the generator mode. Scientific papers of Donetsk National Technical University. Series: Mining and electromechanical, 2001, no.27, pp. 278-282. (Rus).

2. Odnolko D.S. Mathematical simulation of sensorless vector control induction motor under parametric perturbations. System analysis and applied information science, 2015, no.2, pp. 31-35. (Rus).

3. Principle of operation of soft starters: equipment for electric drive control. Available at: https://www.softstarter.ru/plavnijpusk/upp/princip dejstviya/ (accessed 15 October 2015). 
4. Controllers-optimizers EnergySaver: equipment for electric drive control. - Available at https://www.softstarter.ru/catalog/plavnij-pusk/energysaver/. (accessed 22 May 2016).

5. Makarov A.M., Sergeyev A.S., Krylov Ye.G., Serdobintsev Yu.P. Sistemy upravleniia avtomatizirovannym elektroprivodom peremennogo toka: ucheb. posobie [Control systems automated AC drive. Tutorial]. Volgograd, VolgGTU Publ., 2016. 192 p. (Rus).

6. Dementyev Yu.N., Chernyshev A.Yu., Chernyshev I.A. Elektricheskii privod: ucheb. posobie [Electric drive. Tutorial]. Tomsk, TPU Publ., 2010. 232 p. (Rus).

7. Anisimov V.A., Gornov A.O., Moskalenko V.V. Thyristor starting devices in AC drives. Drive and control, 2002, no.1, pp. 32-34. (Rus).

8. Cherepanov V.P., Khrulev A.K. Tiristory i ikh zarubezhnye analogi: spravochnik [Thyristors and their foreign counterparts. Directory]. Moscow, IP RadioSoft Publ., 2002. 512 p. (Rus).

9. Krasovskiy A.B. Osnovy elektroprivoda: ucheb. posobie [Bases of the electric drive. Tutorial]. Moscow, Publishing House MSTU N.E. Bauman, 2015. 405 p. (Rus).
10. Chernyshev A.Yu., Dementyev Yu.N., Chernyshev I.A. Elektroprivod peremennogo toka: ucheb. posobie [AC electric drive. Tutorial]. Tomsk, Publishing house of Tomsk Polytechnic University, 2011. 213 p. (Rus).

11. Lobov V.Y. Method for research of parametric control schemes by asynchronous motor. Metallurgical and Mining Industry, 2015, no.6, pp. 102-108.

Received 10.02.2017

V.I. Lobov ${ }^{1}$, Candidate of Technical Science, Associate Professor,

K.V. Lobova,

${ }^{1}$ Kryvyi Rih National University,

11, V. Matusevycha Str., Kryvyi Rih, 50027, Ukraine, phone +380 5644090635 ,

e-mail: lobovvjcheslav@gmail.com

How to cite this article:

Lobov V.I., Lobova K.V. The thyristor converter influence on the pulsations of the electromagnetic torque of the induction motor at parametrical control. Electrical engineering \& electromechanics, 2017, no.4, pp. 34-41. doi: 10.20998/2074-272X.2017.4.06. 